\title{
Plant Derived Essential Oil in Ruminant Nutrition - A Review
}

\author{
Khwairakpam Ratika ${ }^{1 *}$ and R.K. James Singh ${ }^{2}$ \\ ${ }^{1}$ Division of Animal Nutrition, ICAR-National Dairy Research Institute, \\ Karnal-132001, India \\ ${ }^{2}$ Division of Veterinary Biotechnology, ICAR-Indian Veterinary Research Institute, \\ Izatnagar, Bareilly-243122, India \\ *Corresponding author
}

\section{A B S T R A C T}

\section{Keywords \\ Essential oils, \\ Ruminant, \\ Performance, Feed additives}

\section{Article Info}

Accepted:

16 April 2018

Available Online:

10 May 2018
Feed additives are products used in animal nutrition to improve the quality of feed and the quality of food from animal origin, or to improve the animals' performance and health. Use of herbal feed additives in animal nutrition is gaining importance due to ban of antibiotics as feed additives because of their possible contribution to emergence of antibiotic resistant bacteria and transferring to humans when they consumed animal products. Therefore, herbal feed additives have attracted public interest, replacing antibiotics. Among the various herbal feed additives, the inclusion of essential oils in ruminant diets is nowadays becoming a common practice, since dietary supplementation has been proven a simple and convenient strategy to modulate ruminal fermentation to improve nutrient utilization in ruminants. A wide range of essential oils have the potential to act as multifunctional feed supplements for animals including effects on growth performance, digestive system, pathogenic bacterial growth and lipid oxidation.

\section{Introduction}

The term essential oil dates back to the $16^{\text {th }}$ century and derives from the drug Quinta essentia, named by Paracelsus von Hohenheim of Switzerland (Guenther, 1948). Essential oils, also known as volatile oils, are aromatic components found in many edible, medicinal, and herbal plants. Essential oils can be extracted from many parts of a plant, including the leaves, flowers, stem, seeds, roots and bark by steam distillation or solvent extraction (Greathead, 2003). But, the composition of the EO may vary among different parts of the same plant (Dorman and
Deans, 2000). EOs are volatile, aromatic compounds synthesised by plants for antibacterial, antifungal and antiviral purposes, and to deter herbivorous insects and animals. They are important aromatic components of herbs and spices and contribute to natural preservation of foods. The antibacterial properties of EOs are well documented and recognised (Kalemba and Kunicka, 2003) both in vitro (Ouwehand et al., 2010) and in vivo (Tiihonen et al., 2010). Essential oil are more recently being investigated as rumen modifiers in ruminants (Wallace, 2005). Essential oils are considered safe for human and animal consumption, and 
are categorized as generally recognized as safe (GRAS; FDA, 2004) in the USA.

The antimicrobial properties of EO have been demonstrated against a wide range of microorganisms, including bacteria, protozoa and, fungi (Chao et al., 2000). Essential oils have also been exploited for their activity against a wide variety of food-borne pathogens. For example, Escherichia coli O157: H7 was inhibited by oregano oil and its two main components carvacrol and thymol (Helander et al., 1998; Elgayyar et al., 2001).

The most important active compounds of EOs are categorized into two chemical groups: (mono- and sesqui-) terpenoids and phenylpropanoids that originate from different precursors of the primary metabolism and are further synthesized through separate metabolic pathways. Terpenoids (limonene, thymol, carvacrol, linalool, etc.) are characterized as deriving from an isoprene unit, namely a basic structure of five carbons ( $\mathrm{C} 5 \mathrm{H} 8)$ through the mevalonate pathway (Zwenger, 2008).

On the other hand, phenylpropanoids (cinnamaldehyde, eugenol, anethole, etc.) derive mainly from the phenylalanine that is synthetized by the shikimate metabolic pathway and are compounds with a chain of three carbons bound to an aromatic ring of six carbons.

EOs and their components are hydrophobic, a characteristic that enables them to partition lipids in the bacterial cell wall and mitochondria, leading to their accumulation in the lipid layer and a disruption of the membrane integrity and ion transport processes, and resulting in disturbances of the cell osmotic pressure. A rapid dissipation of $\mathrm{H}^{+}$and $\mathrm{K}^{+}$ion gradients (proton motive sources) and depletion of the intracellular ATP pool is observed through the reduction of ATP synthesis and the increased hydrolysis. As a result, the trans-membrane electric potential in bacterial cell is reduced and the proton permeability of the membrane is increased slowing down bacterial growth. When the bacterial tolerance threshold is passed, the extensive loss of cell contents or critical molecules and ions leads to cell death (Burt, 2004).

\section{Effects of EOs on rumen fermentation and VFA}

Due to ability of essential oils to modify cell permeability in microbes and their toxicity to some strains of rumen microorganism, particularly the Gram-negative, essential oils are potentially promising natural alternatives to antibiotics and ionosphores for manipulating ruminal fermentation (McIntosh et al., 2003 and Calsamiglia et al., 2007) and improving feed efficiency and nutrient utilization by ruminants.

Gunal et al., (2014) reported that adding essential oils (EO) like anise oil (ANO), cedar wood oil (CWO), cinnamon oil (CNO), eucalyptus oil (EUO), and tea tree oil (TEO) at different levels $(125,250,500 \mathrm{mg} / \mathrm{l})$ had no effect on the proportions of acetate, propionate, or acetate to propionate ratios in comparison with the control when examined in a rumen batch culture study. And the proportions of butyrate were also not affected $(\mathrm{P}>0.05)$ by EO except for CNO cultures where butyrate was lower $(\mathrm{P}<0.05)$ with the 250 and $500 \mathrm{mg} / \mathrm{l}$ cultures. Supplementation of thyme or cinnamon essential oil did not affect total VFA but decreased molar proportion of acetate and ratio of acetate to propionate, and increased the molar proportion of propionate.

Also, rumen molar concentration of butyrate was increased by adding cinnamon but no change was observed with thyme (Vakili et al., 2013). 


\section{Effect of EOs on methane production}

Methane is a potent greenhouse gas and its release into the atmosphere is directly linked with animal agriculture, particularly ruminant production. Enteric methane losses represent $2-12 \%$ of gross energy intake in ruminants depending on diet composition and feed intake (Boadi et al., 2004). So, reduction of $\mathrm{CH} 4$ emissions from enteric fermentation is beneficial both for the animals (improved feed efficiency and productivity) and for the environment (mitigation of greenhouse effects) (Benchaar et al., 2011). Methane is produced by a group of microorganisms called methanogens by the process methanogenesis.

The antimicrobial activity of EO has prompted interest in whether these compounds could be used to inhibit methanogenesis in the rumen. Five essential oils (EOs), namely, clove oil (CLO), eucalyptus oil (EUO), garlic oil (GAO), origanum oil (ORO), and peppermint oil (PEO), were tested in vitro at 3 different doses $(0.25,0.50$, and $1.0 \mathrm{~g} / \mathrm{liter})$ for their effect on methane production by Patra and $\mathrm{Yu}$ (2012) and discerned that all the EOs significantly reduced methane production with increasing doses, with reductions by $34.4 \%$, $17.6 \%, 42.3 \%, 87 \%$, and $25.7 \%$ for CLO, EUO, GAO, ORO, and PEO, respectively, at $1.0 \mathrm{~g} /$ liter compared with the control. Similarly, Kamra et al., (2005) investigated methanol and ethanol extracts of various spices, including fennel, clove, garlic, onion, and ginger for effects on methane production in vitro. Among the extracts tested, methanol extract of garlic was the most effective suppressant of methane, with a $64 \%$ reduction in vitro without adverse effects on feed digestibility.

There was reduction of methane production of $55 \%, 72 \%$ and $71 \%$ respectively with regard to the $1.0,1.5$ and $2.0 \mathrm{~g} / \mathrm{L}$ oregano EO doses, while rosemary EO $(2.0 \mathrm{~g} / \mathrm{L})$ reduced the methane production by $9 \%$ when tested in vitro (Cobellis et al., 2015).

\section{Effect of EOs on nitrogen metabolism}

Rumen microbes synthesized microbial protein that flows to the small intestine and get absorbed by the host which serve as an excellent source of amino acids required for synthesis of milk and meat proteins. Microbial fermentation could lead to protein losses as ammonia that is environmental pollutants.

Essential oils could also positively influence protein metabolism and reduce rumen ammonia levels and lead to a more efficient utilization of dietary nitrogen by inhibiting deamination, i.e., the breakdown of amino acids to $\mathrm{NH}_{3}$, possibly through the selective limitation of the activity of a specific group of bacteria within the rumen, the "hyperammonia-producing (HAP) bacteria" (Prevotella spp., Ruminobacter amylophilus, etc.) at the level of attachment and colonization (McIntosh et al., 2003 and Calsamiglia et al., 2007). The HAP bacteria comprise only around $1 \%$ of the rumen bacterial populations, but they possess a very high deamination activity (Russell et al., 1988; Wallace, 2004). This could decrease the rate of ammonia production in the rumen, which may be beneficial nutritionally by increasing the efficiency of protein utilization in the rumen (Wallace et al., 2002). Sallam et al., (2011) reported dramatically declined in ammonia nitrogen by inclusion of essential oil of Menthamicrophylla at different dose levels $(0,25,50$ and $75 \mu 1 / 75 \mathrm{ml}$ buffered rumen fluid) to a basal substrate $(50 \%$ roughage: $50 \%$ concentrate). Busquet et al., (2006) demonstrated that some EO (i.e., anise oil, cade oil, capsicum oil, cinnamon oil, clove, bud oil, dill oil, garlicoil, ginger oil, oregano, oil, and tea tree oil) and their main components (i.e., anethol, benzyl salicylate, carvacrol, carvone, cinnamaldehyde, and 
eugenol) markedly inhibited NH3-N et al., (2014) at concentration of 0, 30, 300 concentration at high concentrations (i.e., and $600 \mathrm{mg} /$ litre (ppm) of total culture fluid $3000 \mathrm{mg} / \mathrm{l}$ ), but effects were marginal at and ammonia nitrogen concentration were moderate doses (i.e., $300 \mathrm{mg} / \mathrm{l}$ ) and non- studied in vitro using buffalo rumen liquor and existent at low doses (i.e., $3 \mathrm{mg} / \mathrm{l}$ ).

revealed that ammonia-N concentration was decreased significantly $(\mathrm{P}<0.05)$ with all the Four essential oils i.e. cinnamon, garlic, four essential oils but was found minimum oregano and rosemary oils were tested by Roy with oregano oil at dose of 600ppm (Table 1).

Table.1 Examples of some essential oils and their main components (Chao et al., 2000)

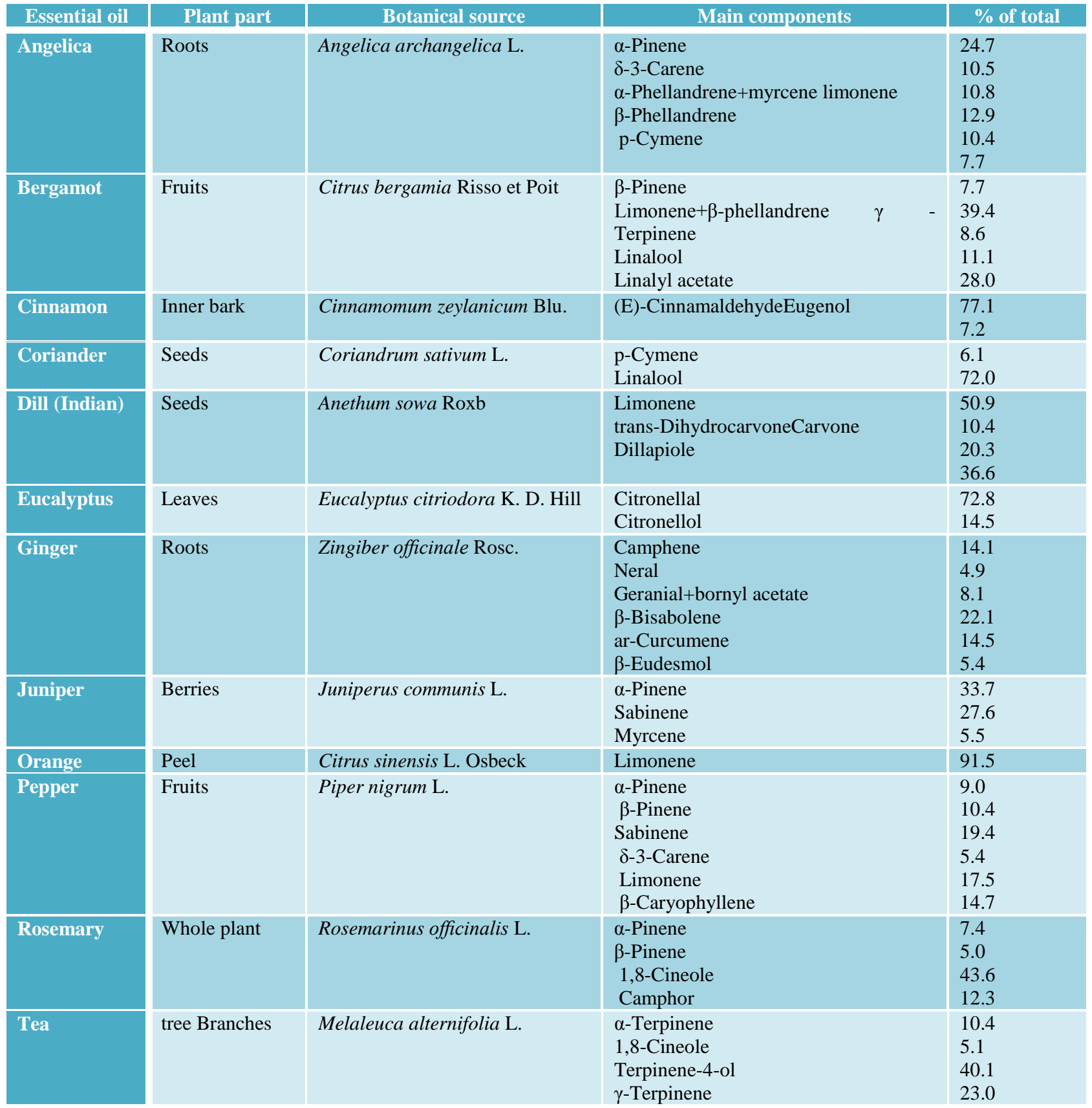




\section{Effects of EOs on ruminant performance}

Essential oils (EO) have been shown to positively impact in vitro ruminal fermentation, but there are few in vivo studies that have examined animal responses. Several essential oils have antimicrobial properties that may affect rumen metabolism and influence milk production parameters. Spanghero et al., (2007) reported that the dietary EOs (blend of oregano, cinnamon, thyme and orange peel Eos) supplementation had no effect on dry matter (DM) intake, water consumptions or faecal DM. Also, milk and milk component yields were not affected by EO feeding level. Valero et al., (2014) observed better final weight, average daily gain, feed efficiency and hot carcass weight for bulls supplemented with 3 grams to animal day ${ }^{-1}$ of essential oils (cashew and castor oils) than for bulls fed control diet. But the feed intake, apparent digestibility, carcass conformation and tissue composition remain unaffected by the additives addition and concluded that the addition of essential oils in the diets of bulls finished in feedlot improve animal performance and carcass weight. Santos et al., (2010) evaluated the efficacy of an EO complex, containing eugenol, geranyl acetate and coriander oil as major components, on the production of lactating dairy cows and found out that DM intake was numerically lower with EO feeding but milk yield was not impacted.

Essential oils have an antibacterial activity against Gram-negative and Gram-positive bacteria (Helander et al., 1998). Several Gram-positive bacteria are involved in ruminal biohydrogenation of unsaturated dietary fatty acids (Harfoot and Hazlewood, 1988). Therefore, feeding EO could lower biohydrogenation of fatty acids by reducing the number, and the activity, of bacteria involved in the biohydrogenation of unsaturated fatty acids. There was no change in milk fatty acid profile when cows were supplemented daily with $750 \mathrm{mg}$ of mixture of essential oils. Supplementing the same mixture at a higher concentration (i.e., 2 $\mathrm{g} /$ day) increased the concentration of conjugated linoleic acid (CLA), a healthpromoting fatty acid, in milk fat (Benchaar $e t$ al., 2007).

Essential oil can be used as herbal feed additives in place of antibiotics to alter rumen fermentation, to improve nutrient utilization by ruminants. Due to antimicrobial properties against gram positive and gram negative bacteria, essential oils are found to be effective strategy to reduce methane emission from rumen fermentation.

\section{References}

Benchaar, C. and Greathead, H. 2011. Essential oils and opportunities to mitigate enteric methane emissions from ruminants. Anim. Feed Sci. Technol. 166: 338-355.

Benchaar, C., Petit, H. V., Berthiaume, R., Ouellet, D.R., Chiquette, J., Chouinard, P.Y., 2007. Effects of essential oils on digestion, ruminal fermentation, rumen microbial populations, milk production, and milk composition in dairy cows fed alfalfa silage or corn silage. J. Dairy Sci. 90: 886-897.

Boadi, D., Benchaar, C., Chiquette, J. and Massé, D. 2004. Mitigation strategies to reduce enteric methane emissions from dairy cows: Update review. Can. J. Anim. Sci. 84:319-33.

Burt, S. 2004. Essential oils: Their antibacterial properties and potential applications in foods-A review. Int. J. Food Microbiol. 94: 223-253.

Burt, S.A., Reinders, R.D., 2003.Antibcaterial activity of selected plant essential oils against Escherichia coli O157: H7. Lett. Appl. Microbiol. 36: 162-167.

Busquet, M., Calsamiglia, S., Ferret, A., Kamel, C. 2006. Plant extracts affect in vitro 
rumen microbial fermentation. J. Dairy Sci. 89, 761-771.

Calsamiglia, S., Busquet, M., Cardozo, P.W., Castillejos, L. and Ferret, A. 2007. Essential oils as modifiers of rumen microbial fermentation. Journal of Dairy Science. 90: 2580-2595.

Chao, S.C., Young, D. G. and Oberg, C.J., 2000.Screening for inhibitory activity of essential oils on selected bacteria, fungi and viruses. J. Essent. Oil Res. 12: 639649.

Cobellis, G., Petrozzi, A., Forte, C., Acut, G., Orru, M., Marcotullio, M. C., Aquino, A., Nicolini, A., Mazza, V. and TrabalzaMarinucci, M. 2015. Evaluation of the Effects of Mitigation on Methane and Ammonia Production by Using Origanum vulgare $\mathrm{L}$. and Rosmarinus officinalis $\mathrm{L}$. Essential Oils on in Vitro Rumen Fermentation Systems. Sustainability. 7: 12856-12869.

Dorman H.J.D. and Deans S.G., 2000. Antimicrobial agents from plants: antibacterial activity of plant volatile oils. In: J. Appl. Microbiol.88: 308-316.

Elgayyar, M., Draughon, F.A., Golden, D. A. and Mount, J. R. 2001. Antimicrobial activity of essential oils from plants against selected pathogenic and saprophytic microorganisms. J. Food Prot. 64: 1019-1024.

FDA. 2005. Freedom of information summary. Supplemental new animal drug application. NADA 095-735. Monensin Sodium (RUMENSIN 80): Type A Medicated Article for Dairy Cattle. http://www.fda.gov/cvm/FOI/095-735s12 1505.pdf

Greathead, H. 2003. Plant and plant extract for improving animal productivity. In: Proc. Nutr. Soc., 62, p. 279-290.

Guenther, E. 1948. The Essential Oils; D. Van Nostrand Company Inc.: New York, NY, USA, p. 427.

Gunal, M., Ishlak, A., Abu Ghazaleh, A. A. and Khattab, W. 2014.Essential oils effect on rumen fermentation and biohydrogenation under in vitro conditions. Czech J. Anim. Sci. 592(10): 450-459.

Harfoot, C.G. and Hazlewood, G.P. 1988. Lipid metabolism in the rumen. In: Hobson, P.N. (Ed.). The Rumen Microbial Ecosystem. Elsevier Applied Science Publishers, London, UK, pp. 285-322.

Helander, I. M., Alakomi, H. L., Latva-Kala, K., Mattila-Sandholm, T., Pol, L., Smid, E.J., Gorris, L.G. M. and vonWright, A., 1998. Characterization of the action of selected essential oil components on Gram negative bacteria. J. Agric. Food Chem. 46: 3590-3595.

Kalemba, D. and Kunicka, A. 2003. Antibacterial and antifungal properties of essential oils. Current Medicinal Chemistry. 10: 813-829.

Kamra, D. N., Agarwal, N. and Chaudhary, L. C. 2005. Inhibition of ruminal methanogenesis by tropical plants containing secondary plant compounds. In: Soliva, C.R., Takahashi, J., Kreuzer, M. (Eds.), Proceedings of the $2^{\text {nd }}$ International Conference of Greenhouse Gases and Animal Agriculture. ETH Zurich, Zurich, Switzerland, pp.102-111.

McIntosh, F. M., Williams, P., Losa, R., Wallace, R. J., Beever, D. A. and Newbold, C.J. 2003.Effects of essential oils on ruminal microorganisms and their protein metabolism. Appl. Environ. Microbiol. 69: 5011-5014.

Ouwehand, A. C., Tiihonen, K., Kettunen, H., Peuranen, S., Schulze, H. and Rautonen, N. 2010.In vitro effects of essential oils on potential pathogens and beneficial members of the normal microbiota. Veterinarni Medicina. 55: 71-78.

Patra, A. K. and Yu, Z. 2012. Effects of Essential Oils on Methane Production and Fermentation by, and Abundance and Diversity of, Rumen Microbial Populations. Appl. Environ. Microbiol. 78 (12): 4271-4280.

Roy, D., Tomar, S. K., Sirohi, S. K., Kumar, V. and Kumar, M. 2014. Efficacy of different essential oils in modulating rumen fermentation in vitro using buffalo 
rumen liquor. Veterinary World. 7(4): 213-218.

Russell, J. B., Strobel, H. J. and Chen, G. J. 1988. Enrichment and isolation of a ruminal bacterium with a very high specific activity of ammonia production. Applied Environ. Microbiol. 54: 872-877.

Sallam, S.M. A., Abdelgaleil, S.A.M., Bueno, I.C.S., Nassera, M.E.A., Araujo, R. C. and Abdalla, A.L. 2011. Effect of essential oils on ruminal fermentation, microbial population and methane emission in vitro. In: Ranilla M.J. (ed.), Carro M.D. (ed.), Ben Salem H. (ed.), Morand-Fehr P. (ed.). Challenging strategies to promote the sheep and goat sector in the current global context. Zaragoza: CIHEAM / CSIC / Universidad de León / FAO, p. 149-156

Santos, M.B., Robinson, P.H., Williams, P. and Losa, R. 2010. Effects of addition of an essential oil complex to thediet of lactating dairy cows on whole tract digestion of nutrients and productive performance. Anim. Feed Sci. Technol. 157: 64-71.

Spanghero, M., Robinson, P.H., Zanfi, C. and Fabbro, E. 2009. Effect of increasing doses of a microencapsulated blendof essential oils on performance of lactating primiparous dairy cows. Anim. Feed Sci. Technol. 153: 153-157.

Tiihonen, K., Kettunen, H., Bento, M. H. L., Saarinen, M., Lahtinen, S., Ouwehand, A. C., Schulze, H. and Rautonen, N. 2010.
The effect of essential oils on broiler performance and gut microbiota. British Poultry Science. 51: 381-392.

Vakili, A. R., Khorrami, B., Danesh, M. and Parand, E. 2013. The Effects of Thyme and Cinnamon Essential Oils on Performance, Rumen Fermentation and Blood Metabolites in Holstein Calves Consuming High Concentrate Diet. Asian Australas. J. Anim. Sci. 26(7): 935-944.

Valero, M.V., Prado, R.M.D., Zawadzki, F., Eiras, C.E., Madrona, G.S. and Prado, I.N.D.2014. Propolis and essential oils additives in the diets improved animal performance and feed efficiency of bulls finished in feedlot. Acta Sci. Anim. Sci. 36: 419-426.

Wallace, R. J. 2005. Symposium: Plants as animal foods: A case of catch 22? Antimicrobial properties of plant secondary metabolites. Proc. Nutr. Soc. 63:621-629.

Wallace, R. J., 2004. Antimicrobial properties of plant secondary metabolites. Proc. Nutr. Soc. 63: 621629.

Wallace, R. J., McEwan, N. R., McInotoch, F. M., Teferedegne, B. and Newbold, C. J. 2002. Natural products as manipulators of rumen fermentation. Asian-Australasian J. Anim. Sci. 10: 1458-1468.

Zwenger, S. and Basu, C. 2008.Plant terpenoids: Applications and future potentials. Biotechnol. Mol. Biol. Rev.3: $1-7$.

\section{How to cite this article:}

Khwairakpam Ratika and James Singh, R.K. 2018. Plant Derived Essential Oil in Ruminant Nutrition - A Review. Int.J.Curr.Microbiol.App.Sci. 7(05): 1747-1753. doi: https://doi.org/10.20546/ijcmas.2018.705.203 